\title{
Evaluación y validación de la prueba de qPCR para el control y monitoreo de diatomeas del género Pseudo-nitzschia en las bahías de Guaynuna y Salinas
}

\author{
Mora Marcela $^{1 *}$, Ascón Darleni², Hung Armando ${ }^{1 *}$

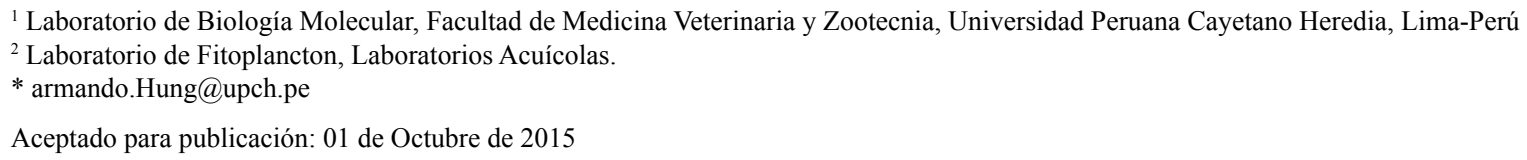

\section{RESUMEN}

La proliferación desmedida de la diatomea del género Pseudo-nitzschia, en conjunto o no con otros grupos de microalgas, conforman las llamadas floraciones de algas nocivas (FAN) las cuales generan un gran impacto negativo en la salud humana, el ecosistema marino y las actividades económicas relacionadas. Objetivo: Evaluar y validar el método molecular qPCR para el control y monitoreo de la diatomea del género Pseudo-nitzschia responsable de producir la toxina amnésica (ASP). Metodología: Se tomaron un total de 63 muestras de agua de mar durante el periodo de noviembre 2012 a diciembre 2013. Las muestras fueron recolectadas en las Bahías de Guaynuna y Salinas (Perú) las cuales presentan como principal actividad económica el cultivo de moluscos bivalvos. Se realizó la concentración de las muestras, extracción de ADN y qPCR utilizando el fluorocromo SYBR Green. Como prueba de referencia se utilizó la observación de las muestras mediante el microscopio óptico invertido. Resultados y conclusiones: Se logró detectar 6.3 x $10^{1}$ células L ${ }^{-1}$ de Pseudo-nitzschia, mostrándose una sensibilidad de la prueba de $100 \%$ y $89 \%$ de especificidad. La técnica molecular validada es altamente eficiente y por lo tanto aplicable para la detección de los fenómenos de floraciones de algas nocivas en el ecosistema marino de nuestro país, considerándola como una alternativa al método tradicional de microscopía y pudiendo ser utilizada como un sistema de alerta temprana.

\footnotetext{
ABSTRACT

A real time qPCR was developed and validated for monitoring Pseudo-nitzschia algae producing the amnesic toxin (ASP). Proliferation of this harmful algae alone or with other toxic algae results in the harmful algae bloom (HAB) which are a risk for public health and aquaculture activities by contamination of the marine ecosystem. The molecular assay developed could detect low concentrations of these algae, at level of $6.3 \times 10^{1}$ cells $\mathrm{L}^{-1}$ with a $89 \%$ of specificity and $100 \%$ sensitivity. A Guaynuna and Salinas bay which holds a main bivalve mollusk culture production were monitored every fortnight from November 2012 to December 2013. This is the first report of using a real time qPCR for identification and quantification of Pseudo-nitzschia in our country. This molecular assay is highly sensitive for detection of HAB, and migth be useful as an alternative to the microscopic method.
} 


\section{INTRODUCCIÓN}

Las floraciones de algas nocivas (FAN) hacen referencia a cualquier proliferación de microalgas (fitoplancton), independientemente de su concentración, percibida como un daño por su impacto negativo en la salud pública, la acuicultura, el medio ambiente y las actividades recreativas. Cuando algunas de estas microalgas que producen potentes toxinas son filtradas por los moluscos bivalvos, las toxinas se acumulan en sus tejidos y se transmiten a niveles superiores de la red alimentaria, incluyendo a los seres humanos. Estas toxinas incluso a bajas concentraciones celulares $\left(10^{3}-\right.$ $10^{4}$ células $\mathrm{L}^{-1}$ ) y $\sin$ que se formen manchas en el agua, pueden convertir a los organismos afectados en no aptos para el consumo (Reguera y col., 2011). Las diatomeas del género Pseudo-nitzschia son productoras de la neurotoxina conocida como ácido domoico (DA) o toxina amnésica (ASP). La producción de ácido domoico suele activarse bajo condiciones de estrés y temperatura del agua (Santiago Morales \& García-Mendoza, 2011) y al ser consumida por los seres humanos conlleva a experimentar síntomas como vómitos, confusión, pérdida de memoria, coma o incluso la muerte (Bates y col., 1989; Bird y col., 1988; Perl y col, 1989; Trainer y col, 2012).

Se ha asociado las FAN con mortalidad y varamientos de leones marinos y delfines en California (Bargu y col., 2012; Buckmaster y col., 2014). Los reportes de impactos socioeconómicos de las FAN en los países de América Latina están creciendo en paralelo con la creciente explotación de sus zonas costeras por las actividades turísticas y la acuicultura (Reguera y col., 2011). Si bien en el Perú no se han reportado casos de intoxicación por ASP hasta el momento, constituye una amenaza permanente que debe ser monitoreada. El mejor conocimiento de las comunidades fitoplanctónicas $\mathrm{y}$ el monitoreo permanente del mar peruano, permitirán desarrollar alertas tempranas sobre semejante eventualidad, y desarrollar estrategias de prevención y mitigación que reduzcan y/o eviten efectos negativos sobre la explotación y cultivo de organismos marinos (IMARPE, 2002).

Los últimos avances en técnicas moleculares vienen siendo de gran importancia para mejorar la detección de especies de fitoplancton productor de toxinas marinas (Litaker y col., 2002). La identificación de Pseudo-nitzschia y de especies FAN puede darse usandouna variedad de marcadores genéticos, como las secuencias de rRNA, regiones D1/D2 LSU, SSU, 5.8S y regiones ITS, entre otras (Adachi y col., 1996; Jhon y col., 2005; Miller \& Scholin 1998; Scholin y col., 1994). En el presente estudio se presenta la validación de una técnica molecular basada en qPCR en tiempo real usando la región ITS-5.8S rDNA (Penna y col., 2007) para la identificación y cuantificación de Pseudo-nitzschia. La técnica validada se utilizó para monitorear la presencia de Pseudo-nitzschia en las bahías de Guaynuna y Salinas, ubicadas al norte del Perú y en las cuales se desarrolla como actividad primaria el cultivo de moluscos bivalvos. Los resultados obtenidos por qPCR fueron comparados con los obtenidos mediante la técnica tradicional de microscopia.

En el Perú, no hay reportes del uso de las técnicas moleculares como una herramienta para la detección de especies tóxicas de fitoplancton incluyendo al género Pseudo-nitzschia. Por el contrario se viene empleando el método tradicional de microscopía, siendo poco factible implementar un sistema de alerta temprana que detecte y cuantifique fitoplancton nocivo de forma rápida y precisa. Por este motivo, el presente estudio tiene por objetivo evaluar y validar la técnica de qPCR para la detección, cuantificación y monitoreo de Pseudo-nitzschia en las Bahías de Guaynuna y Salinas.

\section{MATERIALES Y METODOS Muestreo}

Para la validación del método se utilizó un total de 63 muestras de agua de mar provenientes de la Bahía de Guaynuna ubicada en la provincia de Casma, Ancash - Perú y la Bahía de Salinas ubicada en la provincia de Huara, Lima - Perú. Las muestras fueron recolectadas quincenalmente durante el periodo de noviembre del 2012 a noviembre del 2013, usando una red estándar de fitoplancton con malla de 10 micrómetros siguiendo el método de procedimiento de toma de muestra del IMARPE (2010). El filtrado obtenido fue almacenado en botellas plásticas estériles de $1 \mathrm{~L}$ y enviado bajo condiciones de refrigeración al laboratorio de Biología Molecular para su procesamiento. Las 
sub muestras se preservaron con formalina al $20 \%$, para su posterior análisis mediante observación en el microscopio óptico invertido.

\section{Procesamiento de la muestra y extracción de ADN}

Cada muestra con un volumen inicial de 1 litro de agua de mar fueron centrifugadas a $3000 \times \mathrm{g}$ por 10 minutos, el sobrenadante fue descartado obteniéndose el pellet el cual se resuspendió en $350 \mu \mathrm{L}$ de PBS (pH 7.4), volumen inicial que se utilizó para la extracción del ADN siguiendo las instrucciones del protocolo de extracción de ADN genómico para plantas del kit AxyPrep Multisource Genomic DNA Miniprep Kit (Axygen, USA). El ADN obtenido fue eluido con $100 \mu \mathrm{L}$ del buffer de elución del el kit de extracción utilizado y se conservó a $-20{ }^{\circ} \mathrm{C}$ hasta el análisis de qPCR. Todas las muestras fueron extraídas con un control negativo de extracción (agua de grado molecular) para controlar la posible contaminación cruzada.

La determinación cuantitativa de Fitoplancton por microscopio invertidoserealizóutilizando el método SMEWW (2005) basado en el método de Utermöhl $(1931,1958)$ y consiste en la sedimentación de una alícuota de la muestra tomada de agua de mar fijada con formalina al $20 \%$ utilizando una cámara de sedimentación de $25 \mathrm{~mL}$. El volumen de la alícuota a sedimentar se calculó pesando la cámara de sedimentación vacía y después llena de agua, esta diferencia (gramos) será igual al volumen (mililitros) de agua puesto a sedimentar. Se dejó sedimentar la muestra por un tiempo aproximado de 14 horas en un lugar de temperatura estable protegida de exposición directa a los rayos solares y corrientes de aire. La densidad del fitoplancton fue expresada en número de células por litro. La calidad del ADN obtenido se evaluó mediante un espectrofotómetro A260/A280, Nanodrop 2000 UV (Thermo Scientific, USA), estimándose pureza y concentración.

\section{Elaboración de controles positivos}

El producto del PCR fue analizado mediante electroforesis en un gel de agarosa al $1.5 \%$ y su observación en el transiluminador UV. Las bandas obtenidas de un tamaño de 111 pares de base fueron extraídas del gel y purificadas con el kit AxyPrep DNA Gel Extraction (AXYGEN Biosciences, USA), siguiendo las instrucciones del proveedor.
El ADN purificado de los productos PCR fueron analizados por secuenciamiento.

\section{qPCR en tiempo real y elaboración de curvas estándar}

ElqPCR en tiempo real se llevó a cabo en un volumen final de $25 \mu \mathrm{L}$ utilizando el kit Maxima SYBR Green qPCR Master Mix (Thermo Scientific, USA), los primers (cebadores) usados fueron: forward 5'-CGATACGTAATGCGAATTGCAA-3', reverse 5' -GTGGGATCCR CA GACACTCAGA-3' (Penna y col., 2007) a una concentración final de $300 \mathrm{nM}$. La amplificación se llevó a cabo utilizando el termociclador LightCycler Nano (Roche, Alemania) siguiendo un protocolo de $95^{\circ} \mathrm{C} \times 5$ minutos, 40 ciclos de $95^{\circ} \mathrm{C}$ por 15 segundosy $59^{\circ} \mathrm{C}$ por 1 minuto, al final de la corrida se programó una curva de disociación $55^{\circ} \mathrm{C}$ a $95^{\circ} \mathrm{C}$ de $0.5^{\circ} \mathrm{C} / 15 \mathrm{~s}$. Para el PCR se utilizó un control positivo, un control negativo y una muestra blanco (extracción) como parte del aseguramiento de la calidad de los resultados.

La curva estándar fue generada de ADN extraído de las muestras de agua de mar que fueron previamente identificadas y cuantificadas mediante el método de Utermöhl. La muestra utilizada tuvo una concentración total de $2.87 \times 10^{5}$ células $\mathrm{L}^{-1}$ de Pseudo-nitzschia, la curva estándar se estableció mediantes diluciones decimales seriadas 1:10.

\section{Especificidad y sensibilidad del qPCR en tiempo real}

La especificidad de los primers fue corroborada utilizando el programa informático de alineamiento de secuencias (BLAST) y probados en muestras negativas a Pseudo-nitzschia mediante el método tradicional de microscopio óptico invertido. Al mismo tiempo se verificó la especificidad de los primers para eliminar una posible reacción cruzada con otras especies de fitoplancton identificadas en las muestras: Alexandrium minutum, Alexandrium peruvianum, Alexandrium ostenfeldii, Dinophysis acuminata, Dinophysis caudata, Dinophysis rotundata, Karenia sp., Lingulodinium polyedrum, Prorocentrum lima, Prorocentrum mínimum y Protoperidinium crassipes.

La sensibilidad y especificidad del método fue calculada utilizando como herramienta estadística 
la tabla de contingencia, el cual permitió evaluar los parámetros requeridos, haciendo la comparación de los resultados obtenidos mediante la técnica molecular utilizada (qPCR) y los resultados obtenidos mediante la observación bajo el microscopio invertido a 200X y 400X (método de referencia).

\section{Análisis de datos}

La adquisición de los datos del qPCR y los análisis subsecuentes se llevaron a cabo utilizando el Software LightCycler Nano SW 1.1, usando el análisis de temperatura de melting - SYBR Green.

Los parámetros aceptados para la curva estándar fueron; una pendiente ideal de $-3.32(100 \%$ de eficiencia) y con un coeficiente de correlación (r2) mayor o igual a 0.98 . El porcentaje de eficiencia de amplificación fue calculado (10 (-1/slope $)-1) \times 100$. El número de células de Pseudo-nitzschia en las muestras de agua de mar fue calculado por interpolación de $\mathrm{Cq}$ de las muestras en la curva estándar, teniendo en cuenta el volumen de muestra utilizado.

\section{Análisis estadísticos}

Para el análisis de la data obtenida mediante microscopía y qPCR se utilizó el paquete estadístico Stata Versión 12 (Stata Corp, 2011), evaluándose el nivel de correlación a partir de los valores cuantitativos entre ambas pruebas mediante el análisis de correlación de Spearman, a partir del nivel de correlación se obtuvo el coeficiente de determinación $\left(\mathrm{R}^{2}\right)$.

De la evaluación cuantitativa se generaron la variables de diagnóstico para ambas pruebas, definidas como: 0 células $\mathrm{L}^{-1}$ (negativo) y 10 más células $\mathrm{L}^{-1}$ (positivo), estos resultados fueron organizados en una tabla de contingencia de $2 \times 2$ (teniendo como prueba referencial el análisis de microscopía electrónica). Se obtuvieron los valores de concordancia mediante análisis de Kappa, así como los valores de sensibilidad, especificidad, valor predictivo positivo (VPP) y valor predictivo negativo (VPN) para el método validado qPCR. Los resultados fueron analizados con un nivel de significancia de 0.05 .

\section{RESULTADOS}

Procesamiento de la muestra y extracción de ADN El procesamiento de la muestra y la extracción del ADN de muestras de agua de mar resultó ser el apropiado para la matriz utilizada, obteniéndose ADN de buena calidad en concentraciones que variaron entre 3.1 y $37.8 \mathrm{ng} \mu \mathrm{L}^{-1}$.

\section{qPCR en tiempo real-SYBR Green y elaboración de curvas estándar}

Trabajar con el fluorocromo Sybr Green permitió verificar la Tm del producto de PCR deseado. Las muestras positivas a las diatomeas del género Pseudo-nitzschia (Figura 1) mostraron una $\mathrm{Tm}=$ $84.33^{\circ} \mathrm{C}$ (Figura 2). El PCR en tiempo real presentó unos valores de eficiencia de amplificación entre el $88 \%$ al $98 \%$, mostrando unas pendientes de -3.64 $\mathrm{y}-3.37$ respectivamente, el coeficiente de relación fue de $r^{2}=0.99$ (Fig. 3).

\section{Especificidad y sensibilidad del qPCR en tiempo real}

Los primers utilizados resultaron ser altamente específicos (100\%) para la detección de Pseudonitzschia. Las muestras que presentaron una alta concentración de dinoflagelados como Alexandrium minutum, Alexandrium peruvianum, Alexandrium ostenfeldii, Dinophysis acuminata, Dinophysis caudata, Dinophysis rotundata, Dinophysis rotundata, Karenia sp., Lingulodinium polyedrum, Prorocentrum lima, Prorocentrum mínimum y Protoperidinium crassipes, fueron analizadas mediante PCR en tiempo real empleando los primers para detección de Pseudo-nitzschia. Ninguna de las muestras resultó ser positiva. Los resultados obtenidos demuestran que el método validado amplifica únicamente ante la presencia de ADN de Pseudo-nitzschia. Las muestras analizadas por PCR en tiempo real fueron corroboradas mediante electroforesis en gel de agarosa al 1.5\%, obteniéndose un producto PCR con un tamaño de 111 pares de base (Fig. 4).

La sensibilidad y especificidad del método validado fueron medidas mediante la tabla de contingencia (Cuadro 1) el cual indica la distribución de los resultados obtenidos mediante el método de qPCR utilizando como referencia el método del microscopio invertido. A partir de esta distribución, el análisis indicó un nivel de concordancia entre 
ambas pruebas del $90.14 \%$, siendo este resultado estadísticamente significativo $(\mathrm{p}=0.00001) . \quad \mathrm{El}$ análisis demostró una sensibilidad de 100\%, 89\% de especificidad, valor predictivo positivo de $92.30 \%$ y $100 \%$ de valor predictivo negativo.

Los análisis estadísticos arrojan que el método de PCR tiene una especificidad de $89 \%$ a pesar que las secuencias (primers) utilizadas son 100\% específicas y el método validado demuestra que no existe reacción cruzada con otras especies de fitoplancton. La especificidad reportada mediante la tabla de contingencia se debe a que el método de qPCR detectó la presencia de Pseudo-nitzschia en muestras reportadas como negativas mediante la prueba de referencia (microscopio), clasificándolos como falsos positivos, lo cual estadísticamente demuestra que el método molecular validado posee una menor especificidad en comparación al método tradicional, sin embargo de esta manera se demuestra una de las ventajas del método de qPCR el cual es capaz de detectar un menor número de células $\mathrm{L}^{-1}$ que no es capaz de detectar el método del microscopio, reportando como positivas aquellas muestras que el método de microscopio no logró detectar.

Los resultados del análisis de Spearman indicaron una correlación del 0.9844 (Gráfica 1), a partir de la cual se obtiene un coeficiente de determinación $\left(\mathrm{R}^{2}\right)$ de 0.9690. El nivel de correlación entre ambas pruebas fue estadísticamente significativo $(p=0.00001)$.

\section{Monitoreo de las Bahías de Guyanuna y Salinas}

La abundancia de Pseudo-nitzschia durante el periodo estudiado en las Bahías de Guaynuna y

Salinas se muestra en la Fig. 5. Se puede observar una mayor abundancia de células en los meses de primavera-verano 2013 con un total de $2.91 \times 10^{5}$ células $\mathrm{L}^{-1}$ en la bahía de Guaynuna seguido de los meses noviembre - diciembre 2012 llegando a densidades $1.57 \times 10^{5}$ células $\mathrm{L}^{-1}$ en la bahía de Salinas y $1.16 \times 10^{5}$ células $\mathrm{L}^{-1}$ en la bahía de Guaynuna.

Durante los primeros meses de otoño (mayo) se siguió observando la presencia de Pseudo-nitzschia en una menor cantidad $\left(1.23 \times 10^{2}\right.$ células $\left.\mathrm{L}^{-1}\right)$. En temporada de invierno (julio, agosto) no se detectó la presencia de Pseudo-nitzschia tanto en la bahía de Guaynuna como en Salinas. El bloom declinó en los meses de junio a setiembre empezando a incrementar nuevamente a partir de octubre en ambas bahías.

Al igual que las muestras analizadas por qPCR, tomadas durante el periodo de abril a mayo demuestran la disminución de la abundancia de células de Pseudo-nitzschia (123 células $\mathrm{L}^{-1}$ ), las muestras que fueron analizadas mediante el método tradicional, demostraron que las floraciones de Pseudo-nitzschia disminuyeron hasta 160 células $\mathrm{L}^{-1}$ en los meses mencionados siendo este el reporte de células/litro más bajo encontrado.

Sin embargo se calculó que cerca del $12 \%$ de las muestras analizadas y reportadas negativas a Pseudo-nitzschia por el método tradicional; por la prueba de qPCR si se lograron detectar la presencia de Pseudo-nitzschia reportándose muestras con cantidades menores a 100 células $\mathrm{L}^{-1}$, y presentando el método molecular un límite de detección de 6.3 x 10 células $\mathrm{L}^{-1}$. Para confirmar las muestras positivas consideradas como "falsos positivos", fueron nuevamente extraídas y el PCR se realizó por triplicado cumpliendo con los parámetros de aseguramiento de la calidad de los resultados.

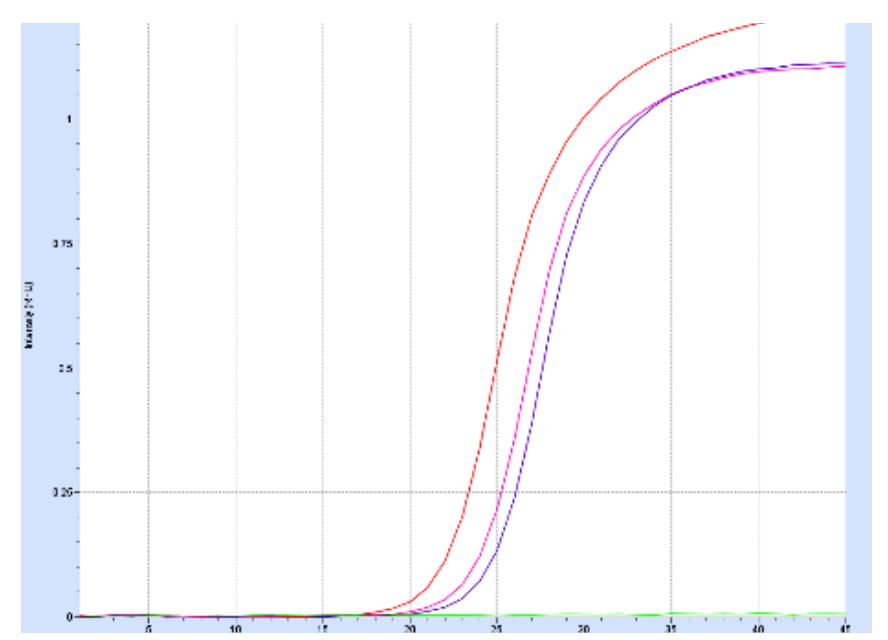

Figura 1 qPCR en tiempo real. Muestras positivas a Pseudo-nitzschia (rosado y morado). Control positivo (rojo). Control negativo (verde) 


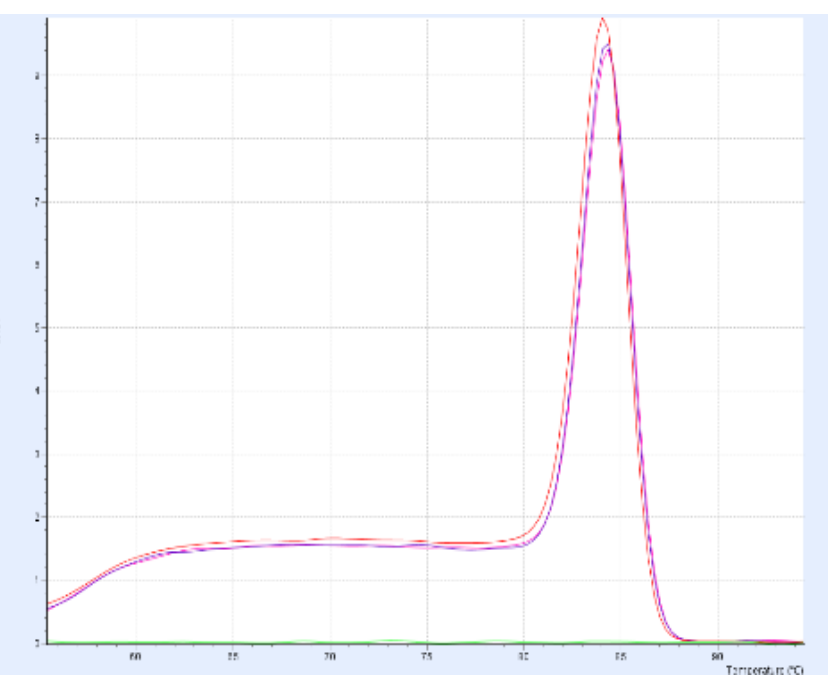

Figura 2 Curva de melting. Muestras positivas presentan una $\mathrm{Tm}=84.33^{\circ} \mathrm{C}$. Control negativo (verde)

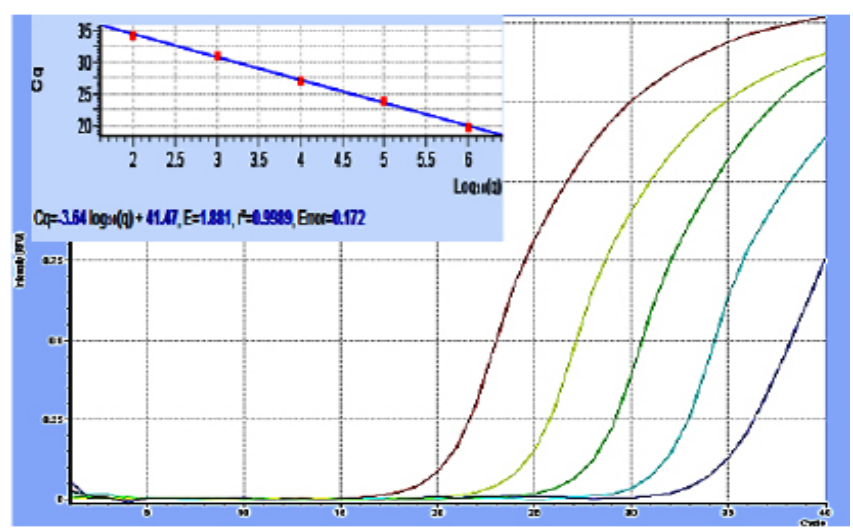

Figura 3 Curva estándar. Construída de ADN extraído de muestras naturales. Diluciones seriadas 105, 104, 103,102, 101. Estándar conc.: 2.87 x 105 células L-1.

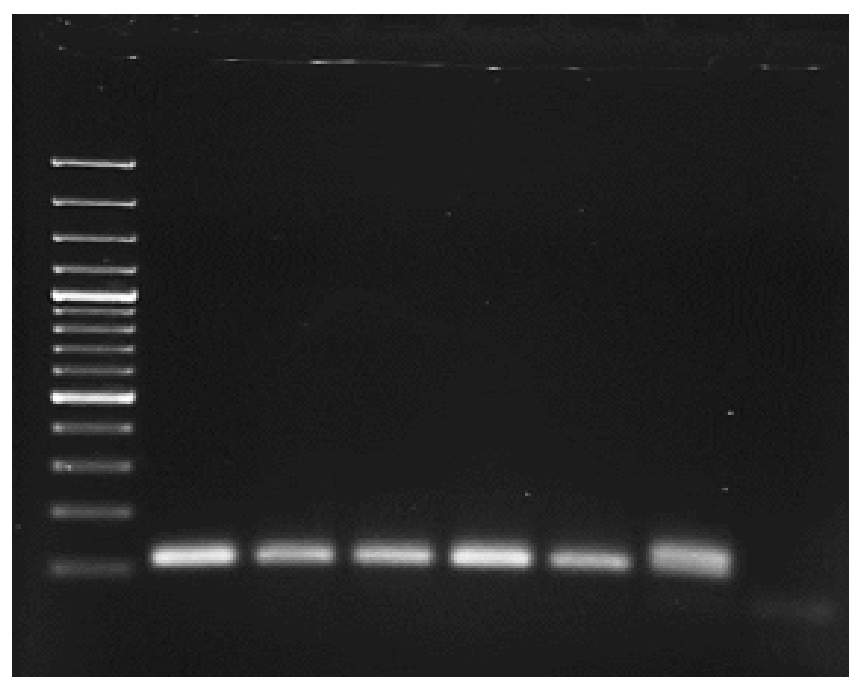

Figura 4 Electroforesis en gel agarosa $1.5 \%$. Ladder 100 bp (a) Bandas de ADN muestras positivas a Pseudo-nitzschia 111 bp (b-f). Control positivo (g). Control negativo (h).

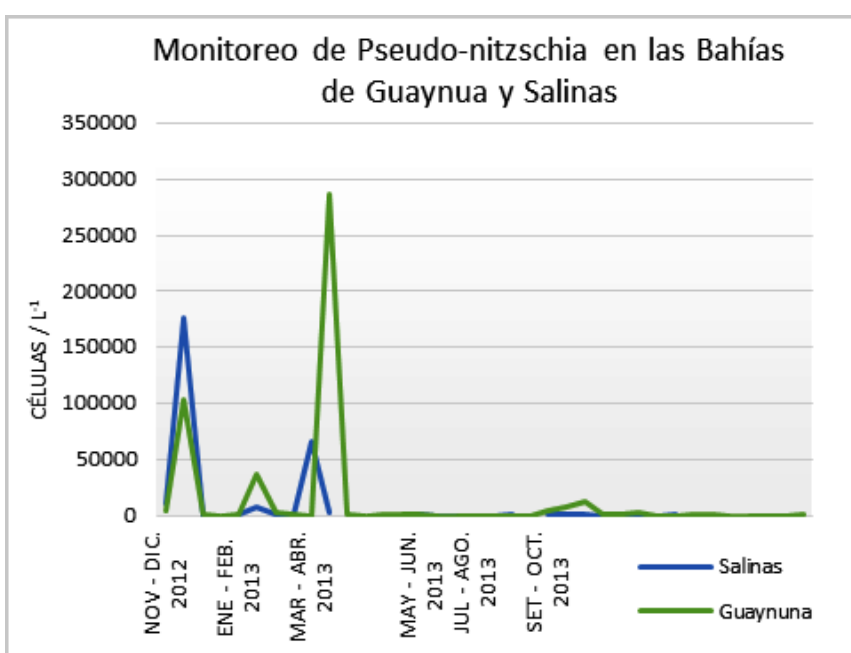

Figura 5 Monitoreo de Pseudo-nitzschia en las bahías de Guaynuna y Salinas durante la temporada noviembre 2012 - noviembre 2013

Cuadro 1. Tabla de contingencia a partir de los resultados cualitativos (positivo o negativo) obtenidos mediante la prueba de microscopía (referencial) y el análisis de qPCR para la detección de Pseudo-nitzchia.

\begin{tabular}{|c|c|c|c|}
\hline \multirow{2}{*}{ qPCR } & \multicolumn{2}{|c|}{ Microscopía (Utermöhl) } & \multirow{2}{*}{ TOTAL } \\
\cline { 2 - 3 } & Positivo & Negativo & \\
\hline Positivo & 36 & 3 & 39 \\
\hline Negativo & 0 & 24 & 24 \\
\hline TOTAL & 36 & 27 & 63 \\
\hline
\end{tabular}

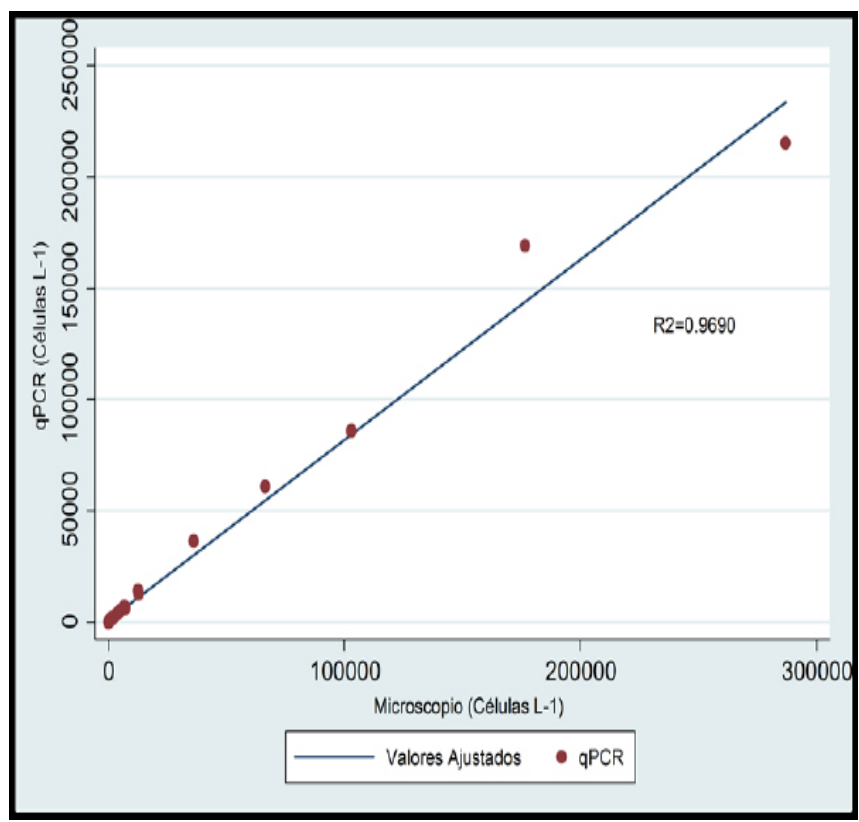

Gráfica 1 Diagrama de dispersión. Demuestra la correlación entre el método de qPCR (Eje Y) y el de microscopía (método Utermöhl - Eje X) para la detección y cuantificación de Pseudo-nitzschia (Formato de Gráfica Stata 12, College Station, TX: Stata Corp LP.) 


\section{DISCUSIÓN}

El método de qPCR validado en el presente trabajo fue empleado como una herramienta de monitoreo para estimar la presencia y abundancia Pseudo-nitzschia en las bahías de Guaynuna y Salinas durante un periodo de 14 meses. Es importante optimizar el monitoreo de las floraciones de algas nocivas que se maneja en el país en términos de sensibilidad, especificidad y rapidez. Para lograr esto, un método fiable, rápido y con un límite de detección inferior al método utilizado actualmente, es necesario. El protocolo desarrollado en el presente trabajo requiere de un mínimo tiempo de análisis, aproximadamente 4 horas, a diferencia de la detección de fitoplancton por microscopio óptico invertido el cual requiere de un mayor tiempo de análisis y de un alto nivel de conocimiento del experto taxonómico.

La primera aplicación de PCR en tiempo real para el monitoreo de fitoplancton tóxico fue a principios del año 2000 llevada a cabo por Bowers y col., posteriormente en el año 2004, Galluzzi trabajó en la detección y cuantificación de Alexandrium minutum en muestras de agua de mar en España, la cuantificación fue realizada utilizando una curva estándar con plásmidos que contenía la secuencia ITS-5.8S rDNA y cultivos celulares, con esto fue posible estimar el número copias de la región 5.8S rDNA por célula y consecuentemente estimar el número de células. Fitzpatrick y col. (2010) trabajaron con Pseudo-nitzschia spp. y a diferencia de Galuzzi, trabajaron curvas estándar construidas de ADN extraído de muestras que fueron inoculadas previamente en agua natural, agua de mar filtrada o en un medio de cultivo, logrando rangos de límite de detección de $0.005-5.2 \times 10^{3}$ células $\mathrm{mL}^{-1}$ para P. australis, $0.004-445.2 \times 10^{3}$ células $\mathrm{mL}^{-1}$ P. delicatissima y $0.055-55.5 \times 10^{3}$ células $\mathrm{mL}^{-1}$ para $P$. pungens en muestras de agua de mar. En el presente trabajo, al igual que Galuzzi se validó el desarrollo de qPCR en tiempo real basado en SYBR Green, se estimó la abundancia celular del género Pseudo-nitzschia mediante curvas estándar de ADN extraído de muestras naturales obteniendo un límite de detección de $6.3 \times 10^{1}$ células $\mathrm{L}^{-1}$. De la misma manera Gaurneau y col. (2011), calibraron el ensayo de qPCR para estimar la abundancia de A. catenella en muestras naturales, directamente según el valor de Ct, la sensibilidad del enfoque de este qPCR en tiempo real permitió la determinación de células con un límite de detección más bajo en relación a la prueba del microscopio óptico invertido $\left(<12\right.$ células $\left.\mathrm{L}^{-1}\right)$. Sin embargo, tiene que considerarse que la determinación del número de copias del ADN target sólo proporciona una correlación aproximada a la cantidad de células en la muestra, ya que no se tiene en cuenta el potencial de variabilidad intra-especie, en el número de copias del gen o el efecto de la fase de crecimiento (Galuzzi y col., 2010). Perini y col. 2011, desarrollaron un método de qPCR en tiempo real basado en SYBR Green I que combina el uso de una curva estándar construida con plásmidos vs. la curva "estándar oro" creada con un pool de extracto crudo de muestras ambientales recolectadas durante una floración de dinoflagelados tóxicos, Ostreopsis cf. ovata en el mar Mediterráneo. La sensibilidad analítica del ensayo de PCR fue de dos copias de genoma rRNA y $8.0 \times 10^{-4}$ células por reacción para el plásmido y la curva "estándar oro", respectivamente.

Las secuencias utilizadas en el método molecular resultaron ser $100 \%$ específicas no se presentó una mayor cantidad de productos no específicos, la identificación de estos productos inespecíficos fueron detectados mediante las curvas de melting usando como referencia la temperatura de melting del control positivo $\left(\mathrm{Tm}=84.33^{\circ} \mathrm{C}\right)$, los productos inespecíficos fueron detectados por presentar usualmente un Ct tardío (36 a más) y una Tm distinta al control positivo. De la misma manera, en los ensayos realizados por Andrée y col. 2011 encontraron productos de PCR no específicos con Ct tardíos, este tipo de dificultades es difícil de evitarlos sin el uso de sondas Taqman o cuando la matriz es tan compleja como el agua de mar donde microalgas, zooplancton, bacterias, virus y otros detritos están presentes. La inmensa biodiversidad del océano se viene describiendo hasta la fecha, y por esta razón el diseño de primers que amplifique algunos productos inespecíficos no interfiere con la señal del target deseado. 
Este tipo de amplificación no debe afectar en la cuantificación de fitoplancton ya que en la mayoría de los casos en los que las células de Pseudonitzschia están presentes, la presencia del target específico disminuye el ruido en las reacciones no específicas como se puede ver mediante los picos en las curvas de melting (Figura 2).

Los resultados obtenidos por qPCR en el presente trabajo, fueron comparados con el recuento bajo microscopía. Ambos métodos se correlacionaron significativamente (Gráfica 1) en cuanto al recuento celular, sin embargo el método molecular fue capaz de detectar células de Pseudo-nitzschia en concentraciones no detectadas por el microscopio. Se encuentra un mayor número de muestras detectadas positivas a Pseudo-nitzschia por el método molecular en comparación a las detectadas por microscopía, se detectaron 3 muestras positivas en las que no se encontró Pseudo-nitzschia por microscopia, Perini y col. 2011, detectó positivas dos muestras en el que no se encontraron células de Ostreopsis por microscopía y Penna et al. 2007, encontraron que los valores de detección positiva de los ensayos obtenidos por PCR excedían entre el $67 \%$ al $8 \%$ en los ensayos identificados por el ensayo de microscopio; $67 \%$ para $P$. reticulatum, 45\% para $L$. polyedrum, $43 \%$ para $A$. tamarense, $38 \%$ para $A$. catenella, $36 \%$ para A. minutum, $33 \%$ para $A$. taylori, 31\% para Dinophysis spp., $20 \%$ para Alexandrium spp. y $8.0 \%$ para Pseudonitzschia spp. Se observó también que a pesar que la cuantificación por ambos métodos fueron altamente comparables, hubo una mayor estimación en relación a la abundancia de células encontradas en cada muestra (células $\mathrm{L}^{-1}$ ) por el método del microscopio en comparación al método molecular, esto se explica que con el fin de obtener una estimación estadísticamente aceptable de la cantidad de células utilizando el método de Utermöhl, se recomienda que al menos 50 unidades deben ser contadas para cada taxón (Rott y col., 2007). Este límite es un problema para las muestras con una baja cantidad de células, como las tomadas en condiciones de no floración o pre floración. Teniendo esto en mente, donde el número de células son bajas, los datos obtenidos a través de los recuentos microscópicos a menudo sobreestiman la abundancia de células y por lo tanto no se consideran altamente fiables, con un error de $200 \%$ (Edler y col., 2010). Por otro lado, cuando se utiliza la microscopía, los volúmenes de muestra se deben ajustar según la abundancia de las especies a identificar. Muestras concentradas necesitan ser diluidas, mientras que las muestras con baja cantidad de células necesitan ser contadas en volúmenes más altos o incluso en múltiples sub-muestras. Estas complicaciones significan que se podría tomar hasta tres semanas para procesar plenamente los análisis de las 63 muestras monitoreadas en este trabajo. Por el contrario, con nuestro método de qPCR en tiempo real validado tardamos unas horas para analizar un conjunto de muestras desconocidas, lo que reduce drásticamente el tiempo de trabajo en comparación con el método tradicional.

El qPCR en tiempo real validado tiene una alta especificidad, sensibilidad y no requiere pericia taxonómica. Por otra parte, la detección oportuna y específica de las especies de algas nocivas antes de las floraciones de algas es un componente crucial de la mayoría de los programas de gestión de FAN y también es una herramienta necesaria para los investigadores que estudian la dinámica demográfica y el desarrollo de modelos para predecir este tipo de eventos. Un método rápido y confiable para la detección de diatomeas del género Pseudo-nitzschia a lo largo de la costa peruana y en las zonas de cultivo de moluscos bivalvos como el validado, es un componente muy importante para un programa de monitoreo de algas productoras de toxinas marinas en el país.

\section{AGRADECIMIENTOS}

Los autores agradecen el aporte económico del proyecto FIDECOM PIPEI 056-2012.

\section{LITERATURA CITADA}

Adachi, M., Sako, Y., \& Ishida, Y. (1996). identification of the toxic dinoflagellatesalexandrium catenella and a. tamarense (dinophyceae) using dna probes and whole-cell hybridization. Journal of phycology, 32(6), 1049-1052

American Public Health Association (APHA). 2005. Standard methods for the examination of water and wastewater. Part 10200. C.1, F.2, c.1. Plankton. 21st Ed. APHA-AWWA-WEF. 10-17 
Andree, K. B., Fernández-Tejedor, M., Elandaloussi, L. M., Quijano-Scheggia, S., Sampedro, N., Garcés, E., \& Diogène, J. (2011). Quantitative PCR coupled with melt curve analysis for detection of selected Pseudo-nitzschia spp. (Bacillariophyceae) from the northwestern Mediterranean Sea. Applied and environmental microbiology, 77(5), 1651-1659

Bargu, S., Goldstein, T., Roberts, K., Li, C., \& Gulland, F. (2012). Pseudo-nitzschia blooms, domoic acid, and related California sea lion strandings in Monterey Bay, California. Marine Mammal Science, 28(2), 237-253

Bates, S. S., Bird, C. J., Freitas, A. D., Foxall, R., Gilgan, M., Hanic, L. A., ... \& Wright, J. L. C. (1989). Pennate diatom Nitzschia pungens as the primary source of domoic acid, a toxin in shellfish from eastern Prince Edward Island, Canada. Canadian Journal of Fisheries and Aquatic Sciences, 46(7), 1203-1215

Bird C, Boyd R, Brewer D, Craft AC, de Freitas ASW Identification of domoic acid as the toxic agent responsible for the PEI contaminated mussel incident: a summary of work conducted at the Atlantic Research Laboratory of the National Research Council, Halifax, Between 13 December, 1987 and 11 January, 1988. National Research Council, Canada, 1988

Bowers, H. A., Tengs, T., Glasgow, H. B., Burkholder, J. M., Rublee, P. A., \& Oldach, D. W. (2000). Development of real-time PCR assays for rapid detection of Pfiesteria piscicida and related dinoflagellates. Applied and Environmental Microbiology, 66(11), 4641-4648

Buckmaster, P. S., Wen, X., Toyoda, I., Gulland, F., \& Van Bonn, W. (2014). Hippocampal neuropathology of domoic acid-induced epilepsy in California sea lions (Zalophus californianus). Journal of Comparative Neurology, 522(7), 16911706

Edler, L., \& Elbrächter, M. (2010). The Utermöhl method for quantitative phytoplankton analysis. Microscopic and molecular methods for quantitative phytoplankton analysis, 110

Fitzpatrick, E., Caron, D. A., \& Schnetzer,A. (2010). Development and environmental application of a genus-specific quantitative PCR approach for Pseudo-nitzschia species. Marine biology, 157(5), 1161-1169

Galluzzi, L. \& Penna, A. (2010). Quantitative PCR for detection and enumeration of phytoplancton. En Microscopic and molecular methods for quantitative phytoplankton analysis $(55,95-102)$ París: Commission of UNESCO IOC Manuals and Guides

Galluzzi, L., Penna, A., Bertozzini, E., Vila, M., Garcés, E., \& Magnani, M. (2004). Development of a real-time PCR assay for rapid detection and quantification of Alexandrium minutum (a dinoflagellate). Applied and Environmental Microbiology, 70(2), 1199-1206

Garneau, M. È., Schnetzer, A., Countway, P. D., Jones, A. C., Seubert, E. L., \& Caron, D. A. (2011). Examination of the seasonal dynamics of the toxic dinoflagellate Alexandrium catenella at Redondo Beach, California, by quantitative PCR. Applied and environmental microbiology, 77(21), 76697680

InstitutodelMardelPerúIMARPE(2002).Monitoreo de fitoplancton potencialmente tóxico en Chincha Pisco. http://www.imarpe.gob.pe/imarpe/index. php?id_seccion $=I 0108030100000000000000$

John, U., Medlin, L. K., \& Groben, R. (2005). Development of specific rRNA probes to distinguish between geographic clades of the Alexandrium tamarense species complex. Journal of plankton research, 27(2), 199-204

Litaker, R. W., \& Tester, P. A. (2002). Molecular methods for detecting and characterizing harmful phytoplankton. Manual of Environmental Microbiology (2nd ed.). ASM Press, Washington, DC, 342-353 
Miller, P. E., \& Scholin, C. A. (1998). Identification and enumeration of cultured and wild Pseudonitzschia (Bacillariophyceae) using speciesspecific LSU rRNA-targeted fluorescent probes and filter-based whole cell hybridization. Journal of phycology, 34(2), 371-382

Penna, A., Bertozzini, E., Battocchi, C., Galluzzi, L., Giacobbe, M. G., Vila, M., \& Magnani, M. (2007). Monitoring of HAB species in the Mediterranean Sea through molecular methods. Journal of Plankton Research, 29(1), 19-38

Perini, F., Casabianca, A., Battocchi, C., Accoroni, S., Totti, C., \& Penna, A. (2011). New approach using the real-time PCR method for estimation of the toxic marine dinoflagellate Ostreopsis cf. ovata in marine environment. PLoS One, 6(3), e17699

Perl, T. M., Bedard, L., Kosatsky, T., Hockin, J. C., Todd, E. C., McNutt, L. A., \& Remis, R. S. (1990). Amnesic shellfish poisoning: a new clinical syndrome due to domoic acid. Canada diseases weekly report $=$ Rapport hebdomadaire des maladies au Canada, 16, 7-8

Reguera, B., Alonso, R., Moreira, A., \& Méndez, S. (2011). Guía para el diseño y puesta en marcha de un plan de seguimiento de microalgas productoras de toxinas. RLA, Proyecto ARCAL.

Rott, E., Salmaso, N., \& Hoehn, E. (2007). Quality control of Utermöhl-based phytoplankton counting and biovolume estimates - an easy task or a Gordian knot?. Hydrobiologia, 578(1), 141-146

Sánchez, S., Guzman, S., \& Guevara, R.. (2010). Manual de procedimientos para el muestreo y ensayo semicuantitativo y cuantitativo de fitoplancton potencialmente toxico. Perú: IMARPE

Santiago-Morales, I. S., \& García-Mendoza, E. (2011). Growth and domoic acid content of Pseudonitzschia australis isolated from northwestern Baja California, Mexico, cultured under batch conditions at different temperatures and two Si: NO 3 ratios. Harmful algae, 12, 82-94
Scholin, C. A., Villac, M. C., Buck, K. R., Krupp, J. M., Powers, D. A., Fryxell, G. A., \& Chavez, F. P. (1994). Ribosomal DMA sequences discriminate among toxic and non-toxic Pseudonitzschia species. Natural toxins, 2(4), 152-165

Trainer, V. L., Bates, S. S., Lundholm, N., Thessen, A. E., Cochlan, W. P., Adams, N. G., \& Trick, C. G. (2012). Pseudo-nitzschia physiological ecology, phylogeny, toxicity, monitoring and impacts on ecosystem health. Harmful Algae, 14, 271-300

Utermöhl, H. (1958). Zur vervollkommnung der quantitativen phytoplankton-methodik. Mitt. int. Ver. theor. angew. Limnol., 9, 1-38

Utermöhl, V. H. (1931). Neue Wege in der quantitativen Erfassung des Planktons. Verh. int. Verein. theor. angew. Limnol, 5, 567-596 